Check for updates

Cite this: RSC Adv., 2018, 8, 39567

\title{
New type of alginate/chitosan microparticle membranes for highly efficient pervaporative dehydration of ethanol $\uparrow$
}

\begin{abstract}
Gabriela Dudek (D)* and Roman Turczyn
A new type of composite alginate membranes filled with chitosan (CS) and three different modified chitosan submicron particles, i.e. phosphorylated (CS-P), glycidol (CS-G) or glutaraldehyde (CS-GA) crosslinked ones, were prepared, and the pervaporation of water/ethanol mixture was investigated. The influence of various chitosan particles and their content on the transport properties of membranes was discussed. It was found that the addition of chitosan particles into the alginate matrix has a prominent effect on the ethanol/water separation efficiency. All tested membranes are characterized simultaneously by a high flux and selectivity, exhibiting advantageous properties, and outperforming numerous conventional materials. The best results were achieved for alginate membranes filled with phosphorylated chitosan particles at $10 \mathrm{wt} \%$, for which separation factor, flux and PSI were equal to $136.2,1.90 \mathrm{~kg} \mathrm{~m}^{-2} \mathrm{~h}^{-1}$ and $256.9 \mathrm{~kg} \mathrm{~m}^{-2} \mathrm{~h}^{-1}$, respectively.
\end{abstract}

Received 21st September 2018 Accepted 19th November 2018

DOI: $10.1039 / \mathrm{c} 8 \mathrm{ra0} 07868 \mathrm{~h}$

rsc.li/rsc-advances

incorporated into the majority of polymeric materials used for

\section{Introduction}

Hybrid membranes are an emerging class of innovative nanostructured materials, suitable for a wide range of practical applications. ${ }^{1-5}$ Over the last two decades, a rapid growth in fabrication methods, mass transport mechanisms and practical applications of hybrid membranes in pervaporation was observed. ${ }^{6-8}$ For the preparation of hybrid membranes several methods have been frequently used, e.g. physical blending method, sol-gel method, in situ polymerization method, etc. Among them, physical blending is the most common and facile fabrication technique because of its independency on the filler preparation or modification. Besides, the respective synthesis of filler phase and membrane favours incorporation of various fillers with different sizes, shapes, porosities and surface functionalities into hybrid membranes, thus enriching their hierarchical structures.

Different kinds of materials can be used as fillers, e.g. metal oxide nanoparticles, ${ }^{9-13}$ silica nanoparticles, ${ }^{\mathbf{1 4 - 1 9}}$ zeolites, ${ }^{\mathbf{2 0 - 2 3}}$ graphene oxides, ${ }^{24-26}$ carbon nanotubes (CNTs) ${ }^{27-29}$ and metalorganic frameworks (MOFs). ${ }^{30-33}$ Nevertheless, the most popular inorganic additives are metal oxide nanoparticles. The broad spectrum of metal oxide nanoparticles that can be introduced into the polymer membrane contains $\mathrm{Fe}_{3} \mathrm{O}_{4}, \mathrm{ZrO}_{2} \mathrm{TiO}_{2}, \mathrm{MgO}$, $\mathrm{CaO}, \mathrm{Al}_{2} \mathrm{O}_{3}, \mathrm{CuO}, \mathrm{SiO}_{2}$ and $\mathrm{ZnO}^{.9-13}$ Each of them can be easily

Department of Physical Chemistry and Technology of Polymers, Faculty of Chemistry, Silesian University of Technology, Strzody 9, 44-100 Gliwice, Poland. E-mail: gmdudek@polsl.pl; Fax: +48 32 2371509; Tel: +48 322371427

$\dagger$ Electronic supplementary information (ESI) available. See DOI: 10.1039/c8ra07868h the fabrication of membrane, showing the fine synergistic properties between the polymeric materials and nanoparticles.

One of the vital advantages of chitosan is the possibility of multifarious modifications, from chemical to physical viewpoints, tailoring for specific purposes. Additionally, biopolymers possess the benefit of widespread availability from marine (chitin and chitosan) or agriculture (cellulose, starch, pectin) resources, as well as the environmental safety because of their biodegradability, biocompatibility and non-toxicity. Furthermore, chitosan nanoparticles (ChNPs) benefit both from the chitosan as a material and its nano-size, e.g. as surface and interface effects, and quantum effects. ${ }^{34}$ Chitosan beads often possess an open-porous structure with interconnected micropores and channels extending from surface to the bead's centre. In this case, bead surface presents a uniform porosity. The rigidity of chitosan beads is supposed to increase the mechanical strength of a membrane material, whereas their pores should enhance the flux affecting the mechanism of diffusion and transport. ${ }^{35-37}$

Keeping above in mind, we have prepared novel organicorganic alginate hybrid membranes filled with pristine chitosan (CS) and three type of fillers of amended chitosan particles with submicron size, i.e. phosphorylated (CS-P), glycidol modified (CS-G) and glutaraldehyde (CS-GA) crosslinked chitosan. Proposed new type hybrid alginate/chitosan membranes differ from described in literature. Generally this both biopolymers are blended together to produce hybrid membranes or are casted layer by layer to form multilayer, asymmetric membranes. Chitosan is soluble in acidic solutions, e.g. $0.1 \mathrm{M}$ acetic acid, but sodium alginate as anionic polymer is better 
soluble in basic solutions, which could rise some problems with the mutual solubility and miscibility. Typically alginate membranes demonstrate better separation performance than chitosan membranes, whereas chitosan one usually exhibits higher fluxes. The approach proposed in this work is very simple, but allows to overcome the aforementioned difficulties and benefits from the advantages of both polymers. In our case membranes consist of alginate matrix with submicron chitosan particles acting as a filler. As it can be seen in the following part, the new type of hybrid alginate/chitosan membranes demonstrate high efficiency in ethanol dehydration process, one of the best mentioned in the literature. What more, they keep the very high selectivity at simultaneous high fluxes.

We evaluated and compared transport as well as separation properties $^{38-42}$ of investigated membranes in the pervaporation process of a water/ethanol mixture and discussed the influence of chitosan particles and their content on the overall effectiveness of separation. The results were compared with a previously described/investigated pristine sodium alginate membrane. Additionally, the physico-chemical properties of the resulting membranes were studied by FTIR spectroscopy, SEM microscopy, EDS analysis, DSC thermal analysis, contact angle and swelling experiments.

\section{Experimental}

\subsection{Materials}

Sodium alginate, chitosan, urea (purity $\geq 98 \%$ ), glutaricdialdehyde $(2.5 \mathrm{wt} \%$ solution in water), sodium hydroxide (purity $\geq 98 \%$ ), orthophosphoric acid (purity $\geq 100 \%$ ), dimethylformamide (for analysis), glycidol (purity $\geq 96 \%$ ), sodium borohydride (purity $\geq 99 \%$ ), sodium periodate (purity $\geq 99 \%$ ), were obtained from Acros Organic. Calcium chloride (purity $\geq$ 96\%), aceticacid (purity $\geq 99 \%$ )were purchased from Avantor Performance Materials.

\subsection{Modification of chitosan particles}

Phosphorylated chitosan (CS-P) particles were prepared based on Sakaguchi et al. method. ${ }^{43}$ In this case, $20 \mathrm{~g}$ of chitosan, $100 \mathrm{~g}$ of urea, and $20 \mathrm{~g}$ of $100 \%$ orthophosphoric acid were added into $200 \mathrm{ml}$ of dimethylformamide. The mixture was stirred and heated at $150{ }^{\circ} \mathrm{C}$ for $1 \mathrm{~h}$. The obtained suspension was cooled to room temperature and separated by centrifugation. The precipitate was thoroughly washed with deionised water and freeze-dried. Glycidol modified chitosan (CS-G) particles were prepared using the modified method of Shainoff. ${ }^{44}$ Briefly, $200 \mathrm{ml}$ of $3 \%$ chitosan solution in $0.15 \mathrm{M}$ acetic acid was mixed with $12 \mathrm{ml}$ of glycidol and $100 \mathrm{ml}$ of $1 \mathrm{M} \mathrm{NaOH}$ containing sodium borohydride $\mathrm{NaBH}_{4}\left(2 \mathrm{mg} \mathrm{ml}{ }^{-1}\right)$ as antioxidant. The solution was then stirred vigorously at $25^{\circ} \mathrm{C}$ for $18 \mathrm{~h}$. Fabricated CS-G particles were washed with distilled water until neutral $\mathrm{pH}$ $(7 \pm 0.5)$. These one step modifications yield glycerol groups, $\mathrm{CS}-\mathrm{O}-\mathrm{CH}_{2}-\mathrm{CHOH}-\mathrm{CH}_{2} \mathrm{OH}$. The resultant $\mathrm{CS}-\mathrm{G}$ was further suspended in $250 \mathrm{ml}$ of water and $70 \mathrm{ml}$ of $0.16 \mathrm{M}$ sodium periodate $\left(\mathrm{NaIO}_{4}\right)$ to transform the vicinal -OH groups into aldehyde groups and formaldehyde molecules. The suspension was kept under slow stirring for $2 \mathrm{~h}$ at room temperature.

Chitosan-glutaraldehyde (CS-GA) crosslinked particles were synthesized based on modified Poon et al. procedure. ${ }^{45}$ Thus, an aqueous $3 \mathrm{wt} \%$ chitosan solution was prepared by dissolving $2 \mathrm{~g}$ of chitosan in $100 \mathrm{ml}$ of $2 \mathrm{vol} \%$ acetic acid solution. Next, the $\mathrm{pH}$ of solution was adjusted to 5.6 by drop-wise adding of $0.01 \mathrm{M}$ $\mathrm{NaOH}$. Then, $1.4 \mathrm{ml}$ of $50 \mathrm{vol} \%$ glutaraldehyde was added to the stirred polymer solution. The precipitated gel was left overnight. Thereafter, $2 \mathrm{M} \mathrm{NaOH}$ was added drop-wise into the aged gel phase for $3 \mathrm{~h}$ until a dark brown suspension was produced and the final $\mathrm{pH}$ reached $c a$. 7. The insoluble crosslinked products were vacuum filtered, subsequently washed with several portions of distilled water and cold acetone. After partial air-drying, prepared CS-GA was crushed and further dried in air for additional $24 \mathrm{~h}$.

\subsection{Membrane preparation}

$1.5 \mathrm{wt} \%$ sodium alginate solution was synthesized by dissolving an appropriate amount of sodium alginate powder in deionised water. The solution was mixed with an appropriate portion of chitosan (CS), and modified chitosan particles, such as phosphorylated chitosan (CS-P), glycidol modified chitosan (CS-G) and chitosan-glutaraldehyde (CS-GA) crosslinked particles (0; $5 ; 10 ; 15 ; 25 \mathrm{wt} \%)$. The sodium alginate solution was then casted onto a levelled glass plate and evaporated to dryness at $40{ }^{\circ} \mathrm{C}$. After $24 \mathrm{~h}$, the membrane was crosslinked using calcium chloride. In this case, sodium alginate membrane was immersed in $2.5 \mathrm{wt} \%$ calcium chloride solution for $120 \mathrm{~min}$ at room temperature. The pristine Alg membrane was prepared in the same manner as above except for the addition of metal oxide nanoparticles. Optimization of the casting method allows for the preparation of homogeneous membranes with reproducible thickness. The membrane thickness was measured using waterproof precise coating thickness gauge MG-401 ELMETRON, estimated as a mean value of at least 10 measurements in different points and equals to $15.0 \pm 1.0 \mu \mathrm{m}$.

\subsection{Membrane characterization}

Membranes were characterized using scanning electron microscope (SEM), differential scanning calorimeter (DSC) and FTIR spectroscopy. Basing on the results of the sorption tests, the degree of swelling was calculated. Contact angles of dry membranes were measured using MDA1300 Handheld USB Metal Microscope. The contact angle was measured immediately after dropping and at intervals of $10 \mathrm{~s}$. To measure the effect of fouling, $1 \mu \mathrm{l}$ droplets of deionised water were placed on the membranes. Scanning electron microscope characterization was done using Phenom Pro-X microscope. FTIR measurements were performed using Perkin Elmer Spectrum Two FTIR spectrometer for scanning the films at ambient temperature, in the spectral range of $650-4000 \mathrm{~cm}^{-1}$, and with the spectral resolution of $2 \mathrm{~cm}^{-1}$. The thermal measurements were performed on Mettler-Toledo DSC 822e calorimeter under nitrogen atmosphere (flow rate $250 \mathrm{ml} \mathrm{min}{ }^{-1}$ ) and heating rate of $10 \mathrm{~K} \mathrm{~min}^{-1}$. The degree of swelling (DS) of the pristine and hybrid Alg 
membranes with different chitosan and modified chitosan particles loading was determined using sorption test. In this case, membranes were immersed in water or ethanol and the mass changes of analysed samples were determined during one week using analytical balance. The degree of swelling (DS) was calculated using following equation:

$$
\mathrm{DS}=\frac{W_{\text {wet }}-W_{\mathrm{dry}}}{W_{\mathrm{dry}}} \times 100(\%)
$$

where $W_{\text {wet }}$ and $W_{\text {dry }}$ are the weight of wet and dry membrane, respectively.

\subsection{Pervaporation experiments}

PV experiments were carried out using the apparatus described in previously published paper under the same conditions. As the feed, an aqueous solution of $96 \mathrm{wt} \%$ ethanol was used. The permeate was collected in a cold trap cooled with liquid nitrogen. Flux was calculated from the measured weight of liquid collected in the cold traps during a certain time intervals at steady-state conditions. The composition of feed, permeate and retentate was analysed using gas chromatography. ${ }^{46}$ For each membrane, the experiment was repeated three times. The results showed the repeatability of measurements and the errors were of the order of few percent. The permeation flux of component $\mathrm{i}$ was calculated using the following equation: ${ }^{47,48}$

$$
J_{\mathrm{i}}=\frac{m_{\mathrm{i}}}{A t}
$$

where $m_{\mathrm{i}}$ is the weight of a component $\mathrm{i}$ in permeate, $A$ is the effective membrane area, $t$ is the permeation time.

Two parameters were used for the description of the separation properties of the membrane, namely separation factor $\left(\alpha_{\mathrm{AB}}\right)$ and selectivity coefficient $\left(S_{\mathrm{c}_{\mathrm{AB}}}\right)$. Separation factor was calculated by: ${ }^{47,48}$

$$
\alpha_{\mathrm{AB}}=\frac{y_{\mathrm{A}} / y_{\mathrm{B}}}{x_{\mathrm{A}} / x_{\mathrm{B}}}
$$

where $x_{\mathrm{A}}, x_{\mathrm{B}}$ are the weight fractions of components $\mathrm{A}$ and $\mathrm{B}$ in the feed [wt\%], $y_{\mathrm{A}}, y_{\mathrm{B}}$ are the weight fraction of components A and $\mathrm{B}$ in permeate, $\mathrm{wt} \%$.

Based on the $\mathrm{I}^{\text {st }}$ Fick's law, the permeation coefficient was determined according to the formula:

$$
P=\frac{J_{\mathrm{s}} l}{\Delta p}
$$

where, $P$ is the permeation coefficient, barrer $=\frac{\mathrm{cm}_{\mathrm{STP}}{ }^{3} \mathrm{~cm}}{\mathrm{~cm}^{2} \mathrm{~s} \mathrm{cmHg}} \times 10^{10}, l$ is the membrane thickness, $\mathrm{cm}$, $\Delta p$ is the difference of vapour pressure at both sides of the membrane, cmHg, $J_{\mathrm{s}}$ is the diffusive mass flux, $\frac{\mathrm{cm}_{\mathrm{STP}}{ }^{3}}{\mathrm{~cm}^{2} \mathrm{~s}}$.

Selectivity coefficient was equal to the ratio of permeability of separated components: ${ }^{47,48}$

$$
S_{\mathrm{c}_{\mathrm{AB}}}=\frac{P_{\mathrm{A}}}{P_{\mathrm{B}}}
$$

In order to compare the separation efficiency of investigated membranes, pervaporation separation index expressed by following equation was used: ${ }^{47,48}$

$$
\text { PSI }=J\left(\alpha_{\mathrm{AB}}-1\right)
$$

where, $J$ is the total permeate flux and $\alpha_{\mathrm{AB}}$ is separation factor.

\section{Results and discussion}

\subsection{Membrane characterization}

3.1.1 FTIR studies. FT-IR spectra of pristine and modified chitosan particles are shown in Fig. 1A. The spectrum of the unmodified chitosan particles showed characteristic peaks of amide I from non-deacetylated amine groups $(\mathrm{C}=\mathrm{O}$ stretching $)$ at $1651 \mathrm{~cm}^{-1}$, amide II (N-H bending overlapped by the amide I band) at $1576 \mathrm{~cm}^{-1}, \mathrm{CH}_{2}$ wagging coupled with $\mathrm{OH}$ in plane deformation at $1380 \mathrm{~cm}^{-1}$, ether group (C-O-C stretching) at $1159 \mathrm{~cm}^{-1}$, secondary hydroxyl group $(\mathrm{C}-\mathrm{OH}$ stretching) and primary hydroxyl and amine groups $\left(\mathrm{C}-\mathrm{OH}\right.$ and $\mathrm{C}-\mathrm{NH}_{2}$ stretching) at $1065 \mathrm{~cm}^{-1}$ and $1030 \mathrm{~cm}^{-1}$, respectively. Phosphorylation led to an emerging shoulder at $1374 \mathrm{~cm}^{-1}$ which can be attributed to $\mathrm{P}=\mathrm{O}$ asymmetric stretching from phosphates. The peaks found at 1059, 1029 and $972 \mathrm{~cm}^{-1}$ were due to $\mathrm{P}-\mathrm{OH}$ group vibration. Protonation of chitosan amine functionalities is suggested by the presence of two peaks, both attributed to $-\mathrm{NH}_{3}{ }^{+}$groups, namely the asymmetrical deformation at $1650 \mathrm{~cm}^{-1}$ and the symmetric deformation at $1553 \mathrm{~cm}^{-1}$. The initial amide I and II bands were possibly overlapped by these vibrations.

Poon et al. considered two possible reactions that may occur during the crosslinking of chitosan with glutaraldehyde. The first one may occur through an amine-catalyzed aldol addition or become an acetal derivative, where a substitution reaction occurs between the amine of chitosan and the acetal group. ${ }^{45}$ The crosslinking of chitosan membranes with glutaraldehyde leads to the increase in the absorption at $1675 \mathrm{~cm}^{-1}$. As already stated, it is proposed that mechanism of crosslinking between glutaraldehyde and a free amine on chitosan follows a Schiff's base reaction that results in formation of the $\mathrm{C}=\mathrm{N}$ bond. According to Knaul et al., ${ }^{49}$ the signal of $\mathrm{C}=\mathrm{N}$ vibration can show up anywhere between 1620 and $1680 \mathrm{~cm}^{-1}$, depending on the reacted compounds. The presence of shoulders at 1564 and $1718 \mathrm{~cm}^{-1}$, that are due to the ethylenic and free-aldehydic bonds, respectively, can be observed relatively to the intensity of other peaks. Signal of the C-H stretch increase at $2938 \mathrm{~cm}^{-1}$ and the presence of aliphatic amino group decreases as the intensity of a peak at $1113 \mathrm{~cm}^{-1}$. It indicates that the crosslinking with glutaraldehyde turns the membrane more hydrophobic as the primary amine groups are substituted with an aliphatic chain.

In case of the chitosan film reacting with glycidol and sodium periodate, the significantly larger band at $1035 \mathrm{~cm}^{-1}$ is observed. It should be associated with the etherification, acetal and $\mathrm{C}-\mathrm{N}$ bond formation both from vicinal hydroxyl groups of glycidol moiety and oxidised to aldehyde. 

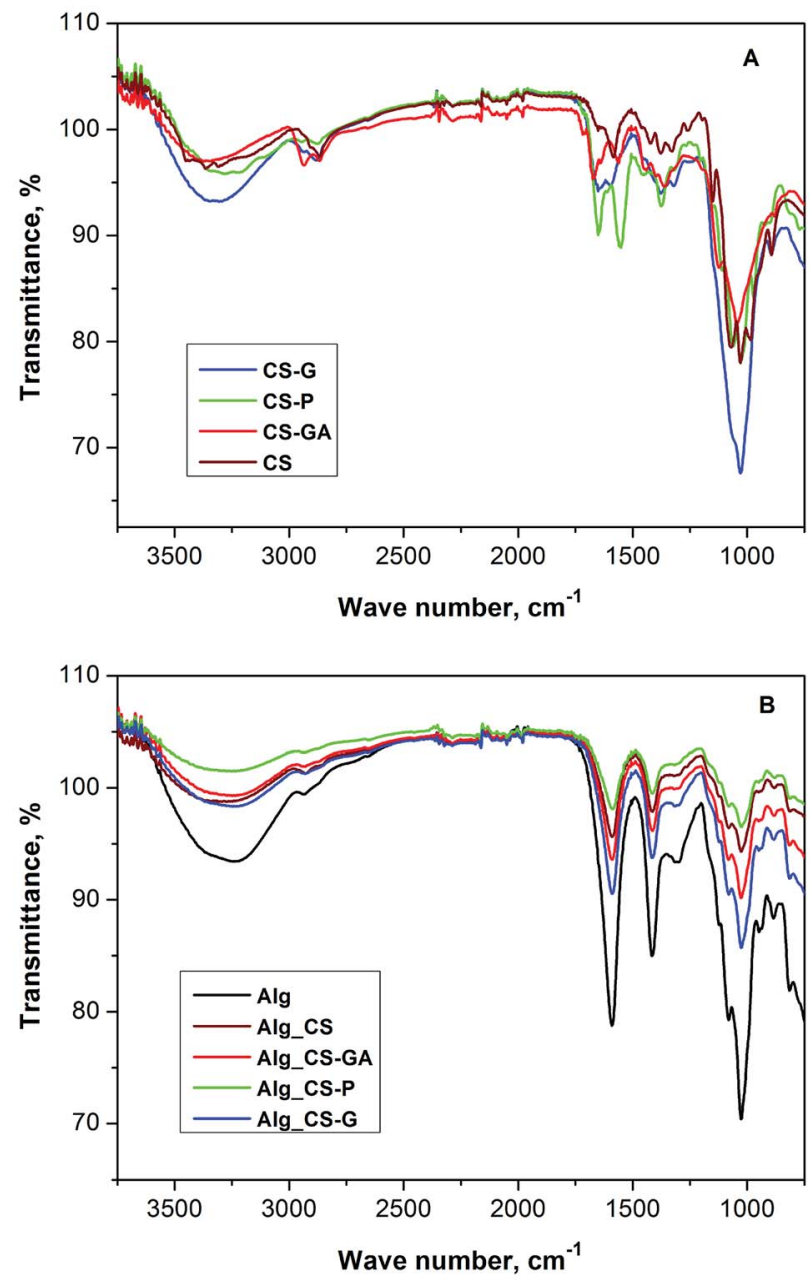

Fig. 1 ATR FTIR spectra of (A) - pristine and modified chitosan particles, and (B) - pristine Alg membrane and series of hybrid Alg membranes filled with modified chitosan particles.

According to Shainoff et al. the addition of glycidol to the chitosan solution leads to etherification in presented reaction: ${ }^{44}$
FT-IR spectra of pristine and hybrid alginate membranes filled with chitosan and modified chitosan particles are shown in Fig. 1B. Pristine alginate membrane shows characteristic bands at $3310,1591,1415$, and $1027 \mathrm{~cm}^{-1}$ corresponding to $\mathrm{O}-\mathrm{H}$ stretching, -COO- asymmetric and symmetric stretching, and C-O-C (ring) vibrational modes, respectively. For hybrid alginate membranes the characteristic peaks of the pristine alginate membranes remain at the same positions but their intensities are significantly smaller. It is due to the fact that the addition of chitosan particles into polymer matrix equals to $10 \mathrm{wt} \%$ in relation to the amount of alginate, so the peaks of chitosan particles are weaker than the peaks of alginate matrix.

3.1.2 DSC studies. DSC thermograms of chitosan modified particles show the influence of the modifying moiety on the polymer stability (Fig. 2A). Pure chitosan exhibited an endothermic peak at $75.4{ }^{\circ} \mathrm{C}$ associated with the evaporation of absorbed water and an exothermic peak at about $311.5{ }^{\circ} \mathrm{C}$ ascribed to the polymer degradation, including saccharide ring dehydration, depolymerisation and decomposition of deacetylated and acetylated chitosan unit.

The glutaraldehyde-crosslinked chitosan tends to retain less water, which in turn volatilizes more easily than it does in the pristine membrane. These finding indicates how intense the membrane-water interactionis, and enables to asset whether the water is loosely or strongly bounded to the chitosan chains. The lower affinity of water in glutaraldehyde-treated membranes indicates more hydrophobic character of chitosan after crosslinking. ${ }^{51}$

The CS-P also shows two stages of weight loss. The first stage of weight loss starts at $25{ }^{\circ} \mathrm{C}$ and continues up to $150{ }^{\circ} \mathrm{C}$. The second stage from 180 to $360{ }^{\circ} \mathrm{C}$ may be contributed to the decomposition of different structures of the phosphorylated chitosan, demonstrating that CS-P is less thermally stable than pristine chitosan. Sodium alginate exhibits an endothermic peak with onset the temperature of $75{ }^{\circ} \mathrm{C}$ and an exothermic peak with the onset at $190{ }^{\circ} \mathrm{C}$ and more complicated shape, caused by the overlapping with another endothermic process. First, endothermic peaks are correlated with the loss of water associated with hydrophilic groups of alginate while exothermic
Treatment of the product of glycidol addition with sodium periodate resulted in the generation of reactive aldehyde functionalities through the oxidation of the glycol moieties: ${ }^{50}$

$$
\begin{aligned}
\mathrm{CS}-\mathrm{O}-\mathrm{CH}_{2}-\mathrm{CHOH}-\mathrm{CH}_{2} \mathrm{OH} \stackrel{\mathrm{IO}_{4}^{-}}{\longrightarrow} & \mathrm{CS}-\mathrm{O}-\mathrm{CH}_{2} \\
& -\mathrm{CHO}+\mathrm{HCHO}
\end{aligned}
$$

peaks results from the degradation of polymer backbone due to dehydration, depolymerisation, saccharide ring destruction, most probably to the partial decarboxylation of the protonated carboxylic groups, than $\mathrm{CO}_{2}$ elimination and chain scission. Satishbabu et al. showed DSC thermograms of the physical mixture of sodium alginate and chitosan showing broad endothermic peak at $81.72{ }^{\circ} \mathrm{C}$, and suggested that it probably 

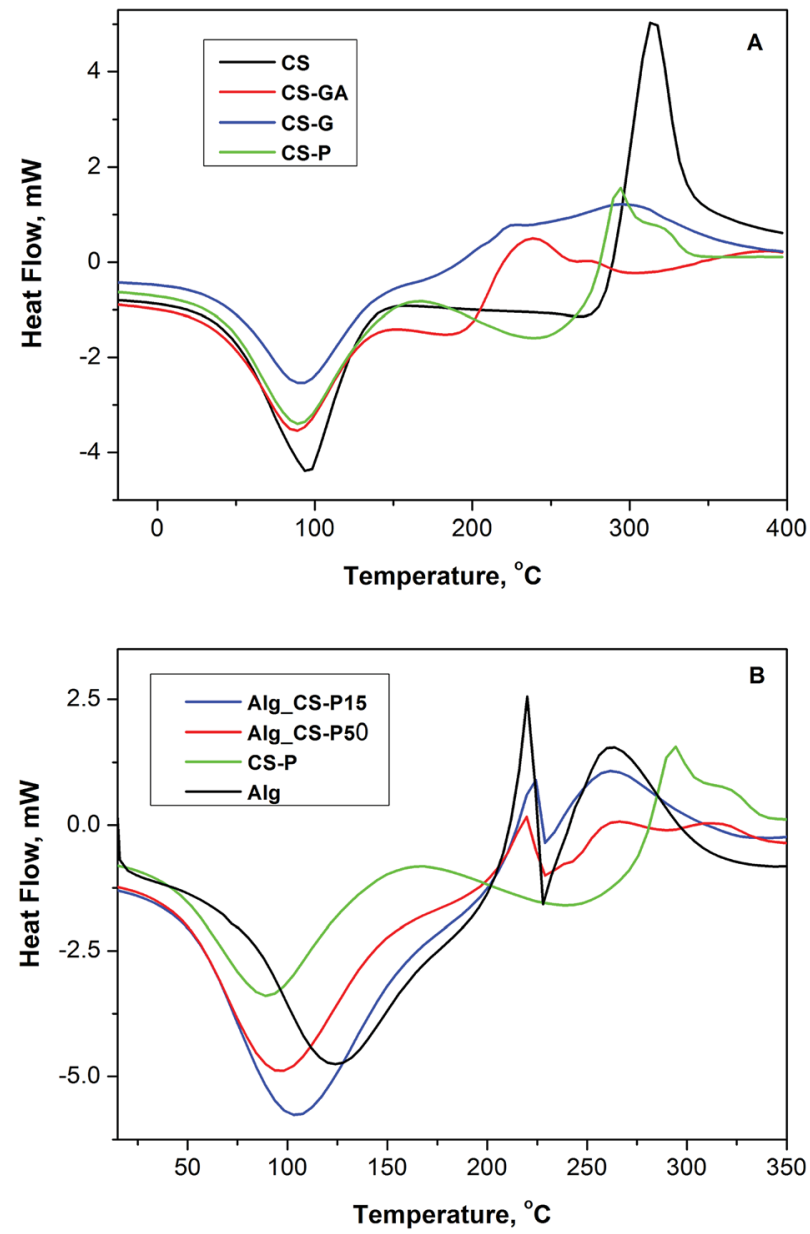

Fig. 2 DSC curves of (A) - series of modified chitosan particles (CS, CS-GA, CS-G, CS-P) and (B) - pristine Alg membrane and two hybrid Alg membranes loaded with $15 \mathrm{wt} \%$ and $50 \mathrm{wt} \%$ of CS-P particles.

represents the coalescence of isolated endothermic dehydration peaks resulting from individual contribution of both polymers. ${ }^{52}$ Formation of the new chemical bonds is expected due to the interaction and complexation between alginate and chitosan. Many researchers postulate the formation of strong insoluble ionic complex layer at the boundary. ${ }^{53}$ The shift of peaks position is expected for such complexes compared to those of the physical mixture, and could be interpreted as an evidence of interaction between both polymers. The intermediate and broader endothermic peak at $80.6{ }^{\circ} \mathrm{C}$ is reported that differ from the one of isolated polyelectrolytes. ${ }^{52}$

In Fig. 2B the thermograms of pristine alginate membrane, pristine CS-P filler and membranes filled with 15 and $50 \mathrm{wt} \%$ of CS-P are compared. Observed changes in the peak position of water loss in case of Alg membranes loaded with CS-P, likewise, points the changes of the hydrophilic character depending on the composition. As expected, it is the unfilled pristine Alg membrane that strongest bounds water, and it is exhibited as the presence of the peak of water loss at higher temperature $\left(125{ }^{\circ} \mathrm{C}\right)$.

This emphatic hydrophilicity of Alg should be associated with the ionic structure of this polymer, i.e. to the presence of carboxylic group in form of anion or salt. With the presence of CS-P particles, the composite becomes gradually less hydrophilic. The temperature of water loss decreases and is equal to 105, 96 and $89^{\circ} \mathrm{C}$ for Alg_CS-P15, Alg_CS-P50 and CS-P itself, respectively. The shift of peaks position as well their symmetry pronounce the strong interaction between Alg matrix and modified CS filler in the investigated composite membranes, independent on the ratio between both components.

3.1.3 Swelling and contact angle measurements. The results of swelling and contact angle experiments for pristine and hybrid sodium alginate membranes with different chitosan fillers are shown in Fig. 3. As a filler pristine chitosan, phosphorylated chitosan (CS-P), glycidol modified chitosan (CS-G) and chitosan-glutaraldehyde (CS-GA) crosslinked particles were used. The results show that all investigated membranes have hydrophilic character and the degree of swelling reaches significantly high values. Comparing alginate and chitosan materials, the higher hydrophilicity is indicated for alginate materials. Carneiro-da-Cunha et al. evaluated the value of contact angle for alginate and chitosan layer. They obtained lower value in case of alginate membrane, explaining that alginate material was more hydrophilic because lower contact angles indicate easier wettable surfaces. ${ }^{54}$

The lowest value of DS (115.22\%) is observed for alginate membranes filled with chitosan-glutaraldehyde particles. This was attributed to the decrease of free $-\mathrm{OH}$ or $-\mathrm{NH}_{2}$ hydrophilic groups in the chitosan particles resulting from the reaction between $-\mathrm{OH}$ or $-\mathrm{NH}_{2}$ groups with aldehyde groups of the GA. ${ }^{55}$ The highest value of DS (238\%) is obtained in case of sodium alginate membranes filled with phosphorylated chitosan. The presence of phosphate group in chitosan matrix impacts on the increase in hydroxyl groups content into obtained particles. The hydroxyl groups have hydrophilic character, influencing the value of the degree of swelling.

The consistent results were obtained in case of contact angle measurement, describing the use of surface hydrophilicity of the membrane for the prediction of the membrane performance. Each experiment was performed eight times to guarantee a statistical integrity. All investigated membranes are

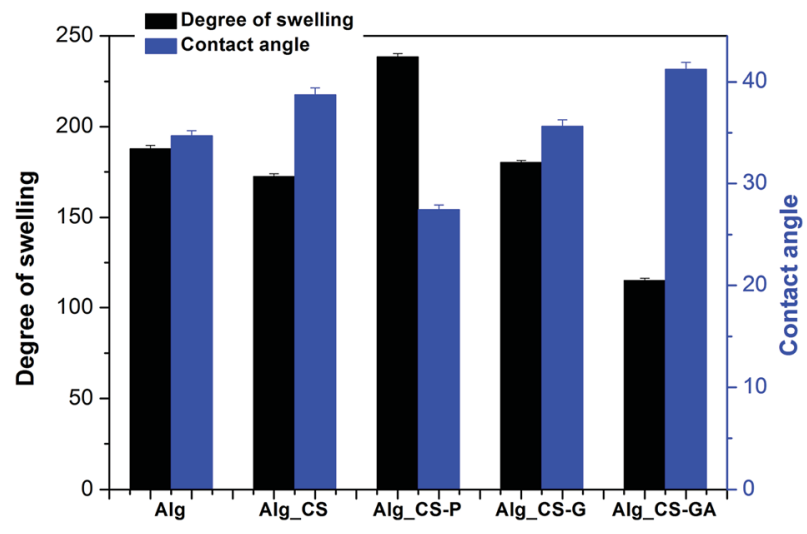

Fig. 3 Contact angles $\theta$ and degree of swelling DS measured for pristine and hybrid alginate membranes filled with modified chitosan particles (average from ten measurements). 
characterized as hydrophilic $\left(q<90^{\circ}\right)$. The contact angle of pristine sodium alginate membrane is equal to $34.7 \pm 0.20$ and the hydrophilicity of the composites is dependent on the kind of chitosan filler and increases in the following order: Alg_CS-GA < Alg_CS $<$ Alg_CS-G $<$ Alg $<$ Alg_CS-P. Like in the case of swelling, the three types of membrane show similar contact angles and are more hydrophilic that Alg_CS-GA. The higher contact angle of Alg_CS-GA membrane results from the hydrophobic nature of the glutaric aldehyde used as a crosslinking agent. The lowest value of contact angle $\left(27.5^{\circ}\right)$ is obtained in case of Alg_CS-P membrane, corresponding with the highest value of a degree of swelling.

3.1.4 Structural properties. Fig. 4(A-C) displays the SEM pictures of CS, CS-G, CS-GA and CS-P particles, as well as the surface and cross-sectional views of Alg membrane with incorporated modified CS particles. From images A, it is visible that the CS particles have irregular shapes and their sizes are located in the submicron range. Chitosan particles usually show bimodal size distribution, consisting from a smaller fraction with the sizes of 150-200 $\mathrm{nm}$ and a larger one with the sizes of 700-1000 nm, which in our case, coincides also with the results of DLS analysis (ESI Table $1 \dagger$ ). It is further noticed (Fig. 4B and C) that the CS particles are evenly distributed throughout the alginate matrix without any signs of clustering. The surface morphology of membranes is uniform with regular wavy sand-like patterned structure without noticeable defects and holes, clearly showing its porous structure. The cross-sectional view of $15 \mathrm{wt} \%$ loaded membranes confirms this suggestion only in case of Alg_CSGA. Nevertheless, the inner structure start to change with the increase in the filler content, as it can be seen in the Fig. 5 that presents images of Alg_CS-P membranes containing 25
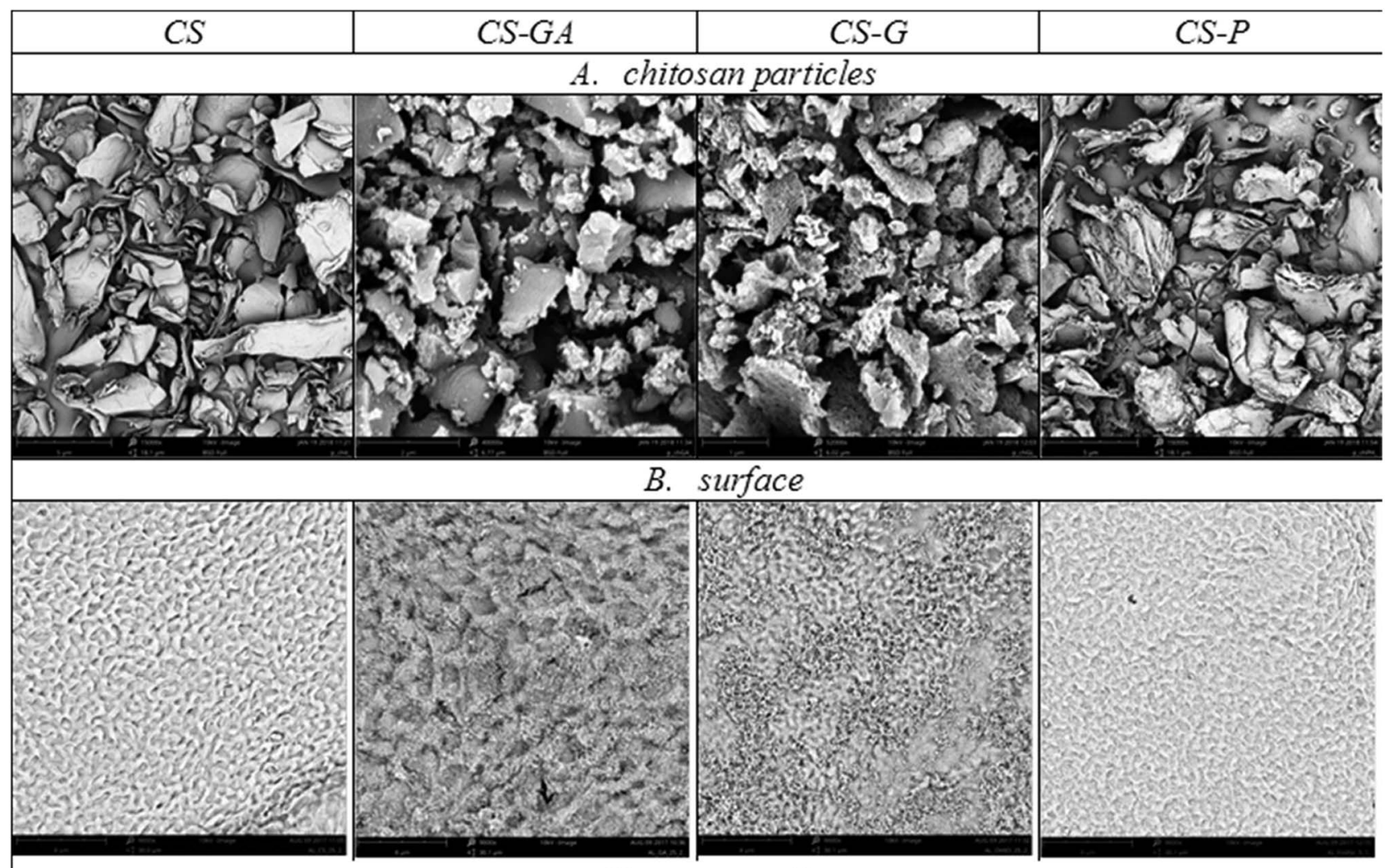

C. cross-section

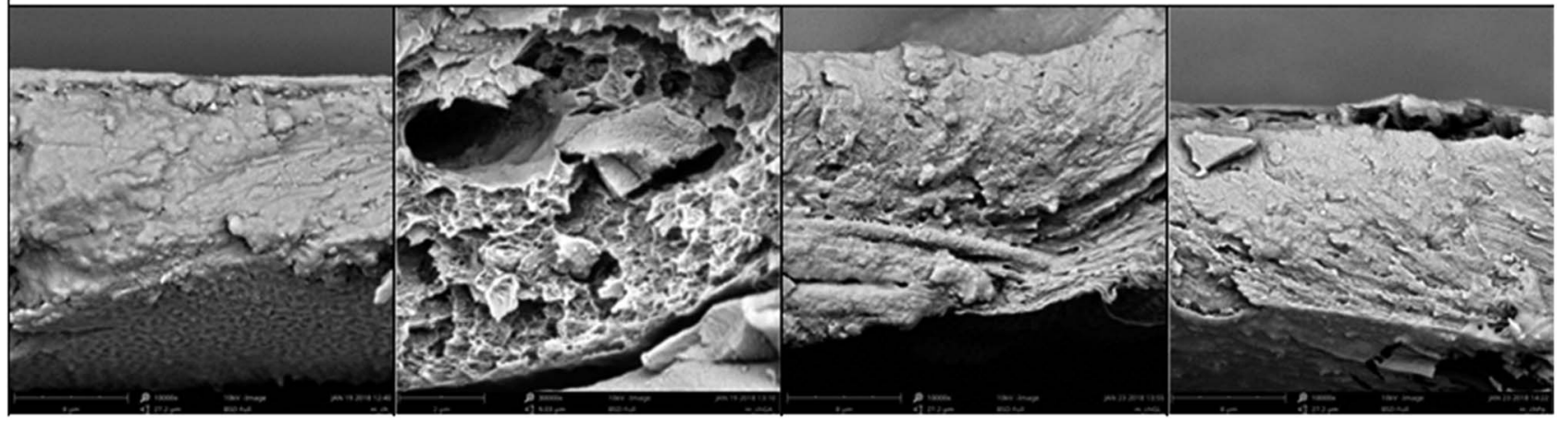

Fig. 4 SEM images of modified chitosan particles and hybrid alginate membranes containing 10 wt\% of filler: (A) modified chitosan particles (magnification $15000 \times$ ); (B) surface and (C) cross-sectional view of hybrid Alg_CS membranes, respectively (magnification 10 000x). 

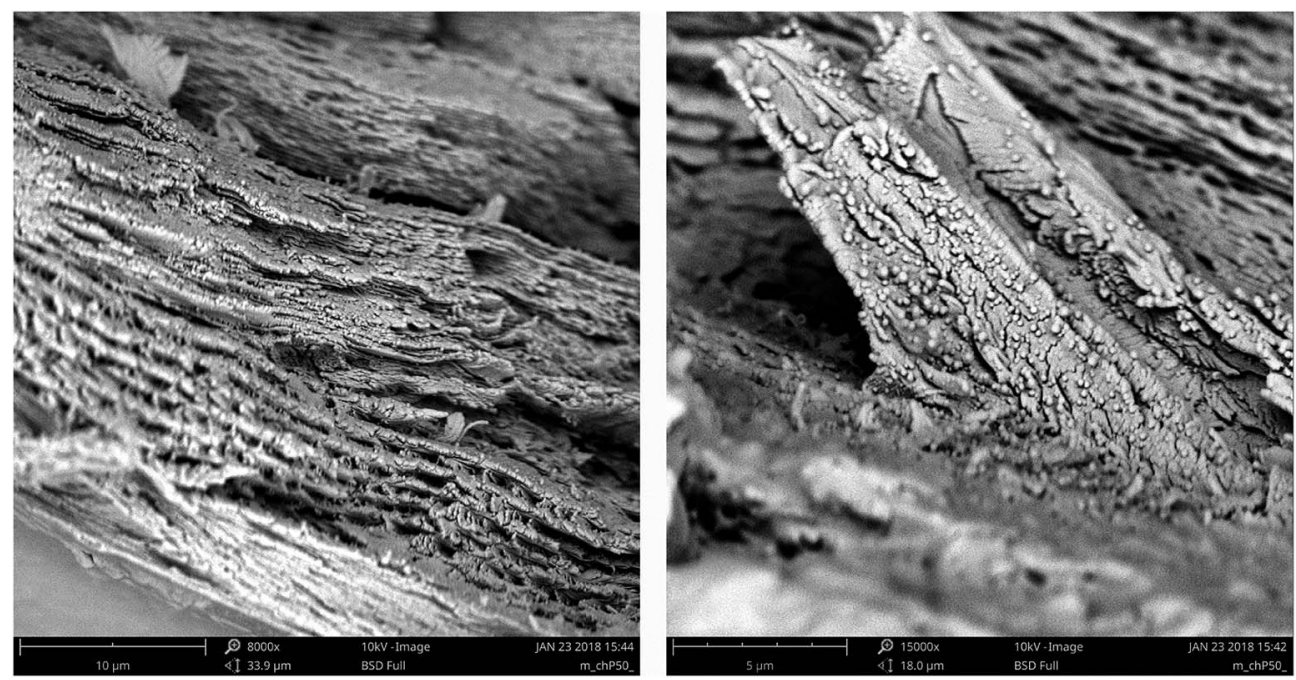

Fig. 5 SEM images of Alg_CS-P membranes containing 25 wt\% of CS-P particles, magnification $8000 \times$ (left) and $15000 \times$ (right).

wt $\%$ of CS-P particles. The results clearly indicate that even at this loading level chitosan particles are still uniformly distributed and dispersed individually in the Alg matrix with the formation of layered lasagne-like structure, where the CS particles are located mainly between the layers. We suppose that such structure facilitates the formation of ionic alginatechitosan complex, associated with the presence of ionised functional groups both in CS (cation) and Alg (anion) matrix, that was proposed, e.g. by Kononova et al. ${ }^{53}$ The thickness of all Alg's membranes is about 10-15 $\mu \mathrm{m}$.

\subsection{Pervaporation performance of hybrid alginate membranes}

3.2.1 The hybrid sodium alginate membranes with nonmodified chitosan particles (Alg_CS). The evaluated parameters describing transport properties, i.e. flux, permeation, diffusion, solubility and selectivity coefficients and separation effectiveness, i.e. separation factor and pervaporation separation index, of ethanol and water in pervaporation process through pristine and hybrid sodium alginate membranes filled with different amount of chitosan particles are collected in Table 1. As it can be seen, the sodium alginate membrane is selective and it can be efficiently used in pervaporative dehydration of ethanol. In this case, separation factor and pervaporation separation index are equal to 26.5 and $18.2 \mathrm{~kg} \mathrm{~m}^{-2}$ $\mathrm{h}^{-1}$, respectively. The addition of chitosan particles into alginate matrix has positive impact on separation properties of investigated membranes. The flux increases twice from 0.71 to $1.41 \mathrm{~kg} \mathrm{~m}^{-2} \mathrm{~h}^{-1}$, for $5 \mathrm{wt} \%$ chitosan content. It is due to the fact that the filler creates free volume into polymer matrix, facilitating the transport of particles. Additionally, Huang et al. explained this phenomenon by the fact that hydrogen bonding are created between sodium alginate and chitosan, allowing for easier transport of water particles through the membrane. ${ }^{56}$ The same relation is observed in case of diffusion and permeation coefficients. The diffusion coefficient of water increases approx.

Table 1 Estimated transport and performance parameters for Alg membranes filled with CS particles

\begin{tabular}{|c|c|c|c|c|c|}
\hline CS particles content, wt $\%$ & 0 & 5 & 10 & 15 & 25 \\
\hline $\operatorname{Flux} J_{N}, \mathrm{~kg} \mathrm{~m}^{-2} \mathrm{~h}^{-1}$ & 0.71 & 1.41 & 1.22 & 1.09 & 0.86 \\
\hline $\begin{array}{l}\text { Diffusion coefficient of water } D_{\mathrm{H}_{2} \mathrm{O}} \times 10^{7} \text {, } \\
\mathrm{cm}^{2} \mathrm{~s}^{-1}\end{array}$ & 1.44 & 5.12 & 4.99 & 4.81 & 4.23 \\
\hline $\begin{array}{l}\text { Solubility coefficient of water } S_{\mathrm{H}_{2} \mathrm{O}} \\
\mathrm{cm}_{\mathrm{STP}}{ }^{3} \mathrm{~cm}^{-3} \mathrm{cmHg}^{-1}\end{array}$ & 335.4 & 170.5 & 169.9 & 168.8 & 147.7 \\
\hline $\begin{array}{l}\text { Solubility coefficient of ethanol } S_{\mathrm{EtOH}}, \\
\mathrm{cm}_{\mathrm{STP}}{ }^{3} \mathrm{~cm}^{-3} \mathrm{cmHg}^{-1}\end{array}$ & 104.5 & 103.0 & 100.0 & 93.7 & 87.1 \\
\hline Selectivity coefficient $S_{\mathrm{c}}$ & 21.0 & 25.7 & 26.5 & 27.1 & 23.1 \\
\hline Separation factor, $\alpha_{\mathrm{H}_{2} \mathrm{O} / \mathrm{EtOH}}$ & 26.5 & 47.3 & 50.2 & 53.6 & 22.1 \\
\hline
\end{tabular}


Table 2 Estimated transport and performance parameters for Alg membranes filled with CS-P particles

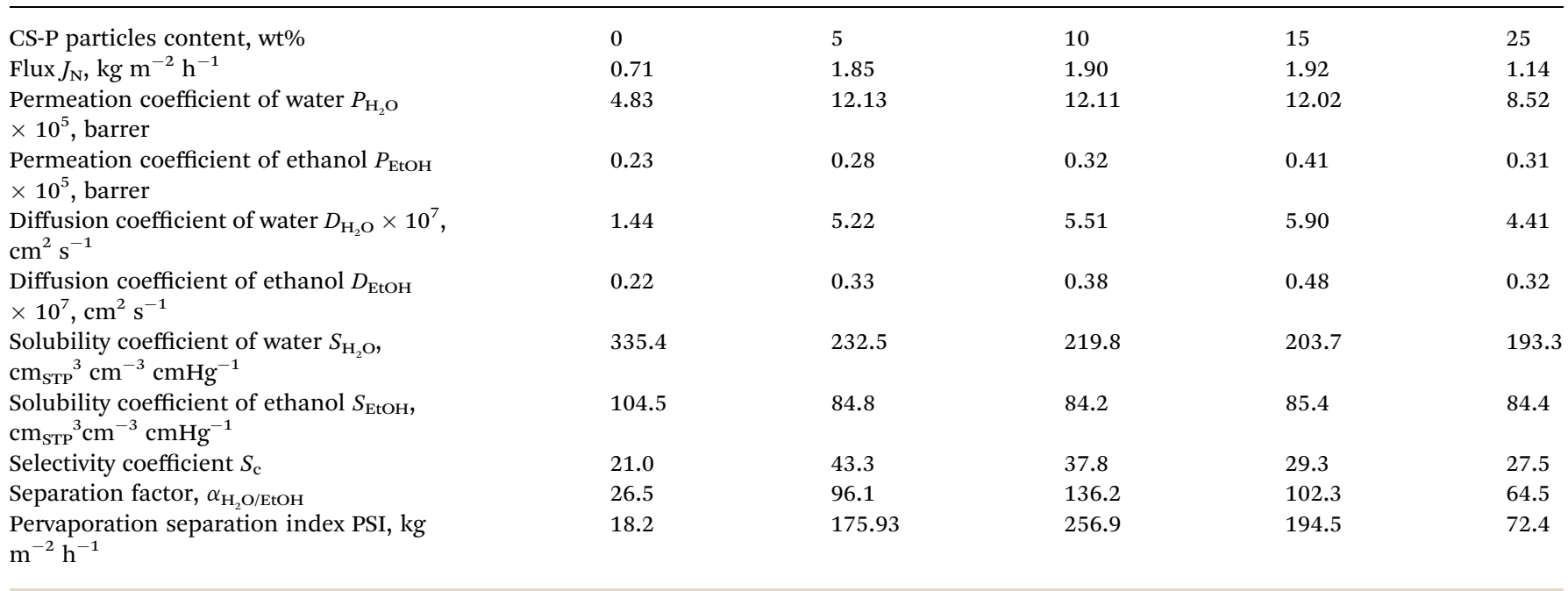

four times from 1.44 to $5.12 \mathrm{~cm}^{2} \mathrm{~s}^{-1}$ and the permeation coefficient of water increases twice from 4.83 to 8.73 barrer, for $5 \mathrm{wt} \%$ chitosan content. The another relation between the water diffusion and permeation coefficients of pristine and hybrid alginate membranes is due to the fact that addition of chitosan particles into alginate matrix impacts on decreasing the value of solubility coefficient about twice. This phenomenon is confirmed by Lawrie et al. ${ }^{57}$ According to their studies, the contact angle of the chitosan layer is significantly higher than of alginate layer, illustrating that alginate is more hydrophilic than chitosan. Additionally, the presence of chitosan particles into alginate matrix has a positive impact on the selectivity coefficient, separation factor and pervaporation separation index. In case of $S_{\mathrm{c}}$ and $\alpha_{\mathrm{H}_{2} \mathrm{O} / \mathrm{EtOH}}$, the best results (27.1 and 53.6, respectively) are achieved for $15 \mathrm{wt} \%$ of chitosan content. Otherwise, different relation is observed in the case of PSI. The addition of more than $5 \mathrm{wt} \%$ of chitosan particles decreases the PSI, although up to $15 \mathrm{wt} \%$ content the PSI is still higher than founded for pristine Alg membrane. For Alg_CS membrane with
$5 \mathrm{wt} \%$ chitosan content, PSI reaches the value of $65.3 \mathrm{~kg} \mathrm{~m}^{-2}$ $\mathrm{h}^{-1}$, and is about 3.5 times higher than for the pristine membrane.

3.2.2 The hybrid sodium alginate membranes with phosphorylated chitosan particles as a filler (Alg_CS-P). Table 2 presents the transport and membrane effectiveness parameters, describing hybrid sodium alginate membranes with different amount of phosphorylated chitosan particles as a filler. The results clearly show that the phosphate groups have positive impact on the process of ethanol dehydration. In this case, solubility coefficients of water are higher than for alginate membranes filled with pristine chitosan particles. It could be connected with the presence of hydroxyl moieties in phosphate groups, which influences the hydrophilicity of membranes. Despite that the values of diffusion coefficients are nearly the same as for Alg_CS membranes, the increase in the solubility coefficients results in the increase of permeation coefficients. For Alg_CS-P membrane with 5, 10 and $15 \mathrm{wt} \%$ phosphorylated chitosan particles content, the value of permeation coefficient

Table 3 Estimated transport and performance parameters for Alg membranes filled with CS-GA particles

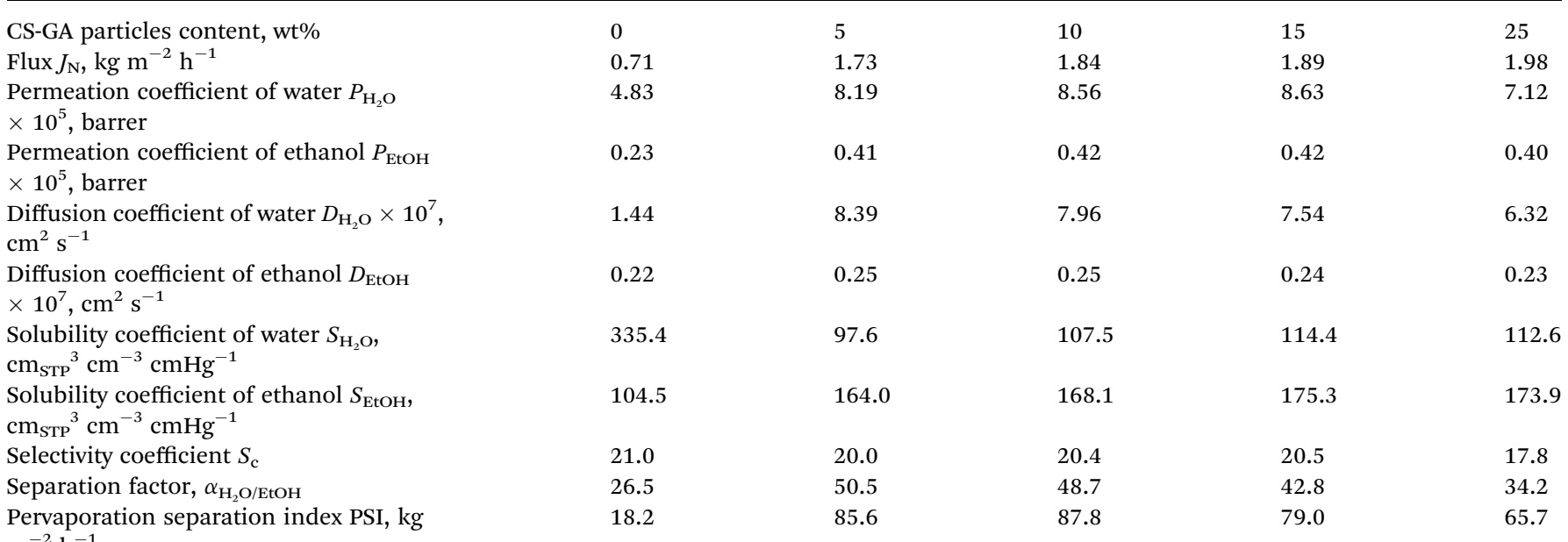


Table 4 Estimated transport and performance parameters for Alg membranes filled with CS-G particles

\begin{tabular}{|c|c|c|c|c|c|}
\hline CS-G content, wt $\%$ & 0 & 5 & 10 & 15 & 25 \\
\hline $\operatorname{Flux} J_{N}, \mathrm{~kg} \mathrm{~m}^{-2} \mathrm{~h}^{-1}$ & 0.71 & 1.77 & 1.88 & 1.82 & 1.95 \\
\hline $\begin{array}{l}\text { Diffusion coefficient of water } D_{\mathrm{H}_{2} \mathrm{O}} \times 10^{7} \\
\mathrm{~cm}^{2} \mathrm{~s}^{-1}\end{array}$ & 1.44 & 7.41 & 7.75 & 7.91 & 8.12 \\
\hline $\begin{array}{l}\text { Solubility coefficient of water } S_{\mathrm{H}_{2} \mathrm{O}} \\
\mathrm{cm}_{\mathrm{STP}}{ }^{3} \mathrm{~cm}^{-3} \mathrm{cmHg}^{-1}\end{array}$ & 335.4 & 201.1 & 153.9 & 117.0 & 85.2 \\
\hline $\begin{array}{l}\text { Solubility coefficient of ethanol } S_{\mathrm{EtOH}} \\
\mathrm{cm}_{\mathrm{STP}}{ }^{3} \mathrm{~cm}^{-3} \mathrm{cmHg}^{-1}\end{array}$ & 104.5 & 103.2 & 93.9 & 81.1 & 71.4 \\
\hline Selectivity coefficient $S_{\mathrm{c}}$ & 21.0 & 34.6 & 26.5 & 18.9 & 13.8 \\
\hline Separation factor, $\alpha_{\mathrm{H}_{2} \mathrm{O} / \mathrm{EtOH}}$ & 26.5 & 65.8 & 57.9 & 51.7 & 40.5 \\
\hline
\end{tabular}

equals to about $12 \times 10^{-5}$ barrer and is about 2.5 times higher than for pristine alginate membrane and about 1.5 times higher than for Alg_CS membranes. The increase in the permeation coefficients of water and nearly the same values of permeation coefficients of ethanol impact on the increase in selectivity coefficients when compared with alginate membranes filled with pristine chitosan particles. The highest value of selectivity coefficient is obtained for Alg_CS-P membrane with 5 wt $\%$ of CS-P particles and equals to 43.3 , twice higher than for pristine alginate membrane and 1.5 times higher than for Alg_CS membrane. The additional phosphate groups present into chitosan chains have also positive influence on the values of fluxes and separation factors. The highest value of flux $\left(1.92 \mathrm{~kg} \mathrm{~m}^{-2}\right.$ $\mathrm{h}^{-1}$ ) is reached for Alg_CS-P membrane with $15 \mathrm{wt} \%$ of filler, and the highest value of a separation factor (136.2) is achieved by the membrane with $10 \mathrm{wt} \%$ of phosphorylated chitosan particles. The increase in both values is the cause of the increase in PSI that reaches the value of $256.9 \mathrm{~kg} \mathrm{~m}^{-2} \mathrm{~h}^{-1}$ for alginate membrane with $15 \mathrm{wt} \%$ of investigated filler. This value is about 14 times higher than for pristine alginate membrane and about 4 times higher than for alginate membrane with 5 wt\% of pristine chitosan particles. The results confirm the work of Sunitha et al. who investigated phosphorylated derivatives of chitosan as membrane in the pervaporative dehydration of ethanol. Their studies showed that phosphorylation of chitosan induces better selectivity without causing of substantial loss in the flux. Hence, ionic crosslinking appears to be a promising technique of enhancing membrane's selectivity with simultaneous retention of its flux. ${ }^{58}$

3.2.3 The hybrid sodium alginate membranes with chitosan-glutaraldehyde (Alg_CS-GA) crosslinked particles. The evaluated parameters describing transport and effectiveness of sodium alginate membranes filled with chitosanglutaraldehyde crosslinked particles are collected in Table 3 . The results show that the addition of chitosan-glutaraldehyde particles into alginate matrix has the significantly impact on the increase of the values of flux. It is due to the fact that crosslinking chitosan by glutaraldehyde extends the chain length between monomers of chitosan, which leads, in consequence, to the increase in the free spaces in the membrane. Wang et al. found that when a hydrophilic membrane was crosslinked with glutaraldehyde, its degree of crystallinity decreased, resulting in an improved flux. This relation is reflected in the values of water and ethanol diffusion coefficients, that are higher than for alginate membrane filled with pristine and phosphorylated chitosan particles. In this case, water diffusion coefficient reaches the value of about $8.0 \mathrm{~cm}^{2} \mathrm{~s}^{-1}$, and ethanol diffusion coefficient equals to about $0.4 \mathrm{~cm}^{2} \mathrm{~s}^{-1} \cdot{ }^{59}$

The addition of CS-GA particles has also the influence on the solubility coefficient of membranes, especially when compared with alginate membranes filled with pristine and phosphorylated chitosan particles. The values of water solubility coefficients are lower and the values of ethanol solubility coefficients are higher. The higher values of water diffusion coefficients and the lower values of solubility coefficients of water compared with alginate membranes filled with pristine chitosan particles

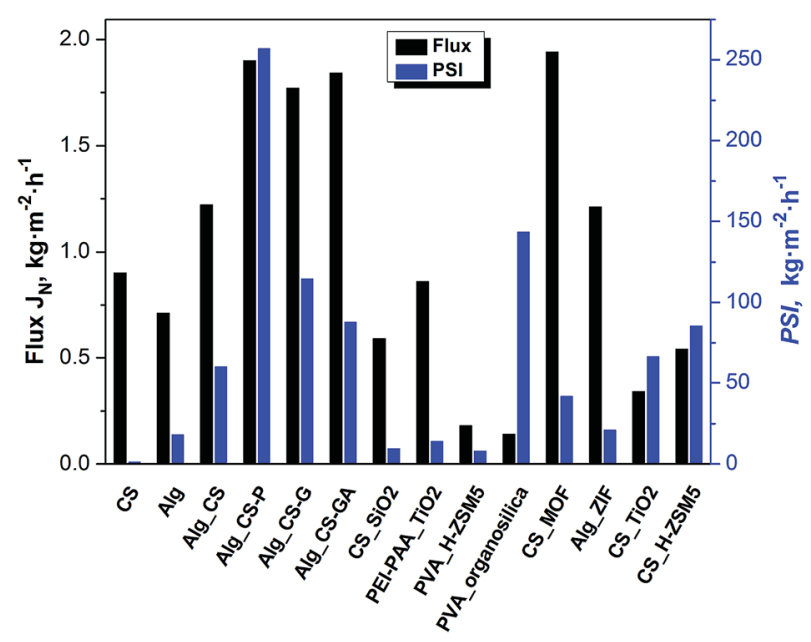

Fig. 6 Comparison of fluxes and the best values of PSI of hybrid Alg_CS membranes with several membrane systems used for pervaporative dehydration of ethanol. 
Table 5 Comparison of performance (flux, separation factor and PSI) of several hybrid membranes for dehydration of ethanol described in literature

\begin{tabular}{|c|c|c|c|c|c|c|}
\hline CS & - & 20 & 0.9 & 2.6 & 1.4 & 60 \\
\hline Alg & CS & 20 & 1.22 & 50.2 & 60.02 & This work \\
\hline Alg & CS-P & 20 & 1.90 & 136.2 & 256.88 & This work \\
\hline Alg & CS-G & 20 & 1.77 & 65.8 & 114.70 & This work \\
\hline CS & $\mathrm{TiO}_{2}$ & 80 & 0.34 & 196.00 & 66.30 & 13 \\
\hline Alg & ZIF & 30 & 1.21 & 18.42 & 21.08 & 14 \\
\hline PVA & Organosilica & 40 & 0.14 & 1026 & 143.50 & 15 \\
\hline CS & $\mathrm{SiO}_{2}$ & 30 & 0.59 & 17.25 & 9.59 & 16 \\
\hline PVA & H-ZSM5 & 30 & 0.18 & 46.00 & 8.10 & 20 \\
\hline CS & H-ZSM-5 & 80 & 0.54 & 158.02 & 85.33 & 22 \\
\hline
\end{tabular}

result in the similarity of water permeation throughout both membranes (water permeation coefficients of 8.50 barrer). Although the values of permeation of coefficient are higher, the evaluated selectivity coefficients are lower than for Alg_CS membranes, and reach the similar values as pristine alginate membrane. As a consequence of increased affinity to ethanol, the values of separation factors of Alg_CS-GA membranes are lower than for Alg_CS-P membranes and reach the similar values as for Alg_CS membranes (50.5 for alginate membrane with $5 \mathrm{wt} \%$ of CS-GA filler). However, for both type of membranes - Alg_CS and Alg_CS-GA - the values of separation factors are similar, notwithstanding, the bigger values of fluxes in case of Alg_CS-GA membranes, have positive impact on the pervaporation separation index. The highest value of PSI (87.8, $\mathrm{kg} \mathrm{m} \mathrm{m}^{-2} \mathrm{~h}^{-1}$ ), is obtained for Alg membrane with $10 \mathrm{wt} \%$ of CSGA particles. This value is about 5 times higher than for pristine alginate membrane and about 1.3 times higher than for alginate membrane with $10 \mathrm{wt} \%$ of pristine chitosan particles which reaches the highest value of PSI.

3.2.4 The hybrid sodium alginate membranes with glycidol modified chitosan particles (Alg_CS-G). Table 4 presents the transport and membrane effectiveness parameters, describing hybrid sodium alginate membranes with different amount of CS-G particles as a filler. As it can be seen, the values of fluxes obtained for alginate membranes filled with CS-G particles are higher than for Alg_CS membranes. Just like in case of alginate membranes filled with chitosan-glutaraldehyde particles, additional chains that are present between chitosan monomers have positive impact on the penetration of water through modified chitosan particles. As a consequence, the values of water diffusion coefficients are higher than $D_{\mathrm{F}}$ evaluated for alginate membranes filled with pristine and CS-P particles, and they increase to the value of $8.12 \mathrm{~cm}^{2} \mathrm{~s}^{-1}$ with the increase the amount of CS-G particles into alginate matrix. In view of the additional hydroxyl groups that appear into glycidol chains, the values of solubility coefficients are higher than for Alg_CS and Alg_CS-GA membranes. The addition of larger quantities of CS$\mathrm{G}$ particles cause the decrease of water solubility coefficient.
This is due to the introduction of carbon chains having hydrophobic properties. As consequence of similar values of water diffusion coefficients and also higher values of solubility coefficients, the resulted water permeation coefficients are higher compared to alginate membranes filled with glutaraldehyde crosslinked chitosan-particles and reach the maximum value of 14.9 barrer for alginate membrane containing $5 \mathrm{wt} \%$ of CS-G particles loaded. The substantial values of flux and separation factors impact on the noticeably high value of PSI. The highest value of pervaporation separation index $\left(114.7 \mathrm{~kg} \mathrm{~m}^{-2}\right.$ $\mathrm{h}^{-1}$ ) is obtained for $5 \mathrm{wt} \%$ Alg_CS-G membrane. The further decrease in PSI at higher concentration of filler is due to the fact that the incorporation of filler into the Alg matrix interfered the polymer chain packing and enhanced effectively fractional free volume, and thus favourable for both water and ethanol diffusing through the membrane.

\subsubsection{Comparison of performance of hybrid membranes} filled with different fillers. The steady-state pervaporation performances for hybrid membranes for ethanol concentration of $90 \mathrm{wt} \%$ at different temperatures are presented in Table 5 and Fig. 6. The results indicate that the newly developed membranes have comparable or superior dehydration performance of ethanol to other membranes. The highest values of fluxes were obtained in case of chitosan membranes filled with metal-organic frameworks $\left(1.94 \mathrm{~kg} \mathrm{~m}^{-2} \mathrm{~h}^{-1}\right)$ and alginate membranes filled with phosphorylated and glutaraldehyde chitosan particles (1.90 and $1.84 \mathrm{~kg} \mathrm{~m}^{-2} \mathrm{~h}^{-1}$ ), investigated in this work. In case of separation factor, the best results were observed for poly(vinyl alcohol) membrane with organosilica particles loaded and chitosan membrane filled with $\mathrm{TiO}_{2}$ and $\mathrm{H}$ ZSM-5 particles (1026, 196.00 and 158.02, respectively) and evaluated in this work for sodium alginate membrane with phosphorylated chitosan particles (136.2). The both flux and separation factor are responsible for the efficiency of the membrane and they are included in PSI. Among all membranes presented in Table 5 the highest values of PSI $\left(256.88 \mathrm{~kg} \mathrm{~m}^{-2}\right.$ $\mathrm{h}^{-1}$ ) has alginate membranes filled with phosphorylated chitosan particles, investigated in this paper. 


\section{Conclusions}

Novel composite organic-organic membranes consisting of organic filler in the form of modified chitosan particles (CS, CSP, CS-GA, CS-G), and crosslinked with calcium cations alginate matrix were prepared for the pervaporation dehydration of ethanol/water mixtures.

The results of conducted separation tests shows that the addition of one polymer in a form of particles as a filler to the another polymer matrix allows to prepare interesting class of membranes and is a very simple and effective manner of significant improvement of the final transport properties. In presented system chitosan filler/alginate matrix, the values of flux and separation factor were about 2.0 times higher, and the PSI was about 3.5 times higher for Alg_CS membrane with 5 wt $\%$ of filler, when compared with the pristine alginate membrane. The further improvement of transport parameters and separation effectiveness was realized by the chemical modifications of chitosan particles. Two of modified chitosan particles (Alg_CS-P, Alg_CS-G) showed enhanced hydrophilicity, thus resulting in higher water affinity of membranes contained them. The best effectiveness of pervaporative ethanol dehydration were obtained for alginate membranes filled with $10 \mathrm{wt} \%$ of phosphorylated chitosan particles. In this case, separation factor, flux and PSI were equalled to $136.2,1.90 \mathrm{~kg} \mathrm{~m}^{-2} \mathrm{~h}^{-1}$ and $256.9 \mathrm{~kg} \mathrm{~m}^{-2} \mathrm{~h}^{-1}$, respectively. The presented organic/organic hybrid membranes possess superior separation factor which comes together with a high flux, what is highly advantageous and not of ten among membranes described in the literature.

\section{Conflicts of interest}

The authors ensure that there are no conflicts to declare.

\section{Acknowledgements}

The authors would like to thank The National Centre for Research and Development and The Silesian University of Technology for providing partial financial support under the following projects: 2018/02/X/ST8/00309 and 04/040/RGH18/ 0088 .

\section{References}

1 R. Singh, Hybrid Membrane Systems for Water Purification, 2005.

2 F. Gao, Advances in Polymer Nanocomposites: Types and Applications, 2012.

3 D. E. Suk and T. Matsuura, Sep. Sci. Technol., 2006, 41, 595626.

4 Inorganic Polymeric and Composite Membranes - Structure, Function and Other Correlations, ed. S. T. Oyama and S. Stagg-Williams, Elsevier, Oxford, 1st edn, 2011.

5 H.-C. Yang, J. Hou, V. Chen and Z.-K. Xu, J. Mater. Chem. A, 2016, 4, 9716-9729.
6 A. Basile, A. Figoli and M. Khayet, Pervaporation, vapour permeation and membrane distillation: Principles and applications, 2015.

7 B. Smitha, D. Suhanya, S. Sridhar and M. Ramakrishna, J. Membr. Sci., 2004, 241, 1-21.

8 G. Jyoti, A. Keshav and J. Anandkumar, J. Eng., 2015, 2015, 124.

9 X. Cheng, F. Pan, M. Wang, W. Li, Y. Song, G. Liu, H. Yang, B. Gao, H. Wu and Z. Jiang, J. Membr. Sci., 2017, 541, 329346.

10 A. Strzelewicz, M. Krasowska, G. Dudek, A. Rybak, R. Turczyn and M. Cieśla, Acta Phys. Pol. B, 2013, 44, 955-965.

11 Y. Wang, L. Yang, G. Luo and Y. Dai, Chem. Eng. J., 2009, 146, 6-10.

12 L. Gong, L. Zhang, N. Wang, J. Li, S. Ji, H. Guo, G. Zhang and Z. Zhang, Sep. Purif. Technol., 2014, 122, 32-40.

13 D. Yang, J. Li, Z. Jiang, L. Lu and X. Chen, Chem. Eng. Sci., 2009, 64, 3130-3137.

14 G. Liu, Z. Jiang, K. Cao, S. Nair, X. Cheng, J. Zhao, H. Gomaa, H. Wu and F. Pan, J. Membr. Sci., 2017, 523, 185-196.

15 L. L. Xia, C. L. Li and Y. Wang, J. Membr. Sci., 2016, 498, 263275.

16 R. P. Pandey and V. K. Shahi, J. Membr. Sci., 2013, 444, 116126.

17 P. V. Naik, L. H. Wee, M. Meledina, S. Turner, Y. Li and G. Van Tendeloo, J. Mater. Chem. A, 2016, 4, 12790-12798.

18 P. H. T. Ngamou, J. P. Overbeek, R. Kreiter, H. M. Van Veen, J. F. Vente and I. M. Wienk, J. Mater. Chem. A, 2013, 1, 55675576.

19 S. Claes, P. Vandezande, S. Mullens, K. De Sitter, R. Peeters and M. K. Van Bael, J. Membr. Sci., 2012, 389, 265-271.

20 D. P. Suhas, T. M. Aminabhavi and A. V. Raghu, Polym. Eng. Sci., 2014, 54, 1774-1782.

21 Y. Wang, X. Zou, L. Sun, H. Rong and G. Zhu, Chem. Sci., 2018, 9, 2533-2539.

22 H. Sun, L. Lu, X. Chen and Z. Jiang, Sep. Purif. Technol., 2008, 58, 429-436.

23 A. Malekpour, B. Mostajeran and G. A. Koohmareh, Chem. Eng. Process. Process Intensif., 2017, 118, 47-53.

24 J. Zhao, Y. Zhu, F. Pan, G. He, C. Fang and K. Cao, J. Membr. Sci., 2015, 487, 162-172.

25 B. Liang, W. Zhan, G. Qi, S. Lin, Q. Nan and Y. Liu, J. Mater. Chem. A, 2015, 3, 5140-5147.

26 H. K. Dave and K. Nath, J. Water Process Eng., 2016, 14, 124134.

27 J. Zhang, Z. Xu, W. Mai, C. Min, B. Zhou and M. Shan, J. Mater. Chem. A, 2013, 1, 3101-3111.

28 A. M. Sajjan, B. K. Jeevan Kumar, A. A. Kittur and M. Y. Kariduraganavar, J. Membr. Sci., 2013, 425-426, 77-88.

29 B. Gao, Z. Jiang, C. Zhao, H. Goma and F. Pan, J. Membr. Sci., 2015, 492, 230-241.

30 B. Gao, Z. Jiang, M. Zhao, H. Wu, F. Pan, J. Q. Mayta, Z. Chang and X. Bu, J. Membr. Sci., 2018, 546, 31-40.

31 A. Kasik and Y. S. Lin, Sep. Purif. Technol., 2014, 121, 38-45.

32 W. Liang, L. Li, J. Hou, N. D. Shepherd, T. D. Bennett, D. M. D'Alessandro and V. Chen, Chem. Sci., 2018, 9, 35083516. 
33 M. S. Denny, J. C. Moreton, L. Benz and S. M. Cohen, Nat. Rev. Mater., 2016, 16078.

34 K. Divya and M. S. Jisha, Environ. Chem. Lett., 2018, 16(1), 101-112.

35 A. Ouyang and J. Liang, RSC Adv., 2014, 4(49), 25835-25842.

36 A. L. Angelim, S. P. Costa, B. C. S. Farias, L. F. Aquino and V. M. M. Melo, J. Environ. Manage., 2013, 127, 10-17.

37 M. Nitsae, A. Madjid, L. Hakim and A. Sabarudin, Chem. Chem. Technol., 2016, 10(1), 105-114.

38 G. Dudek, M. Krasowska, R. Turczyn, M. Gnus and A. Strzelewicz, Sep. Purif. Technol., 2017, 182, 101-109.

39 G. Dudek, M. Gnus, A. Strzelewicz, R. Turczyn and M. Krasowska, Sep. Sci. Technol., 2018, 53(8), 1178-1190.

40 G. Dudek, A. Strzelewicz, R. Turczyn, M. Krasowska and A. Rybak, Sep. Sci. Technol., 2014, 49(11), 1761-1767.

41 G. Dudek, M. Gnus, R. Turczyn and K. Konieczny, Desalin. Water Treat., 2017, 64, 339-344.

42 G. Dudek, R. Turczyn, M. Gnus and K. Konieczny, Sep. Purif. Technol., 2018, 193, 398-407.

43 T. Sakaguchi, T. Horikoshi and A. Nakajima, Agric. Biol. Chem., 1981, 45(10), 2191-2195.

44 J. R. Shainoff, Top. Catal., 1980, 95(2), 690-695.

45 L. Poon, S. Younus and L. D. Wilson, J. Colloid Interface Sci., 2014, 420, 136-144.

46 G. Dudek, M. Gnus, R. Turczyn, A. Strzelewicz and M. Krasowska, Sep. Purif. Technol., 2014, 133, 8-15.

47 J. G. Wijmans and R. W. Baker, J. Membr. Sci., 1995, 107, 121.

48 C. J. Geankoplis,Transport Processes and Separation Process Principles. Transport processes and separation process principles, Upper Saddle River: Prentice-Hall International, 2014.

49 J. Z. Knaul, S. M. Hudson and K. A. M. Creber, J. Polym. Sci., Part B: Polym. Phys., 1999, 37, 1079-1094.

50 J. M. Guisán, Enzyme Microb. Technol., 1988, 10(6), 375-382. 51 M. M. Beppu, R. S. Vieira, C. G. Aimoli and C. C. Santana, J. Membr. Sci., 2007, 301(1-2), 126-130.

52 B. K. Satishbabu, V. R. Sandeep, R. B. Ravi and R. Shrutinag, Indian J. Pharm. Sci., 2010, 72(6), 738-744.

53 S. V. Kononova, A. V. Volod'ko, V. A. Petrova, E. V. Kruchinina, Y. G. Baklagina, E. A. Chusovitin and Y. A. Skorik, Carbohydr. Polym., 2018, 181, 86-92.

54 M. G. Carneiro-da-Cunha, M. A. Cerqueira, B. W. S. Souza, S. Carvalho, M. A. C. Quintas, J. A. Teixeira and A. A. Vicente, Carbohydr. Polym., 2010, 82(1), 153-159.

55 J. H. Chen, X. F. Dong and Y. S. He, RSC Adv., 2016, 6(65), 60765-60772.

56 R. Y. M. Huang, R. Pal and G. Y. Moon, J. Membr. Sci., 2000, 167(2), 275-289.

57 G. Lawrie, I. Keen, B. Drew, A. Chandler-Temple, L. Rintoul, P. Fredericks and L. Grøndahl, Biomacromolecules, 2007, 8(8), 2533-2541.

58 K. Sunitha, S. V. Satyanarayana and S. Sridhar, Carbohydr. Polym., 2012, 87(2), 1569-1574.

59 L. Wang, J. Li, Y. Lin and C. Chen, Chem. Eng. J., 2009, 146(1), 71-78.

60 M. Gnus, G. Dudek, R. Turczyn, A. Tórz, D. Łącka, K. Konieczny and M. Lapkowski, Prog. Chem. Appl. Chitin Its Deriv., 2015, 20, 54-63.

61 Q. Li, Q. Liu, J. Zhao, Y. Hua, J. Sun, J. Duan and W. Jin, J. Membr. Sci., 2017, 544, 68-78. 